\title{
CHANGES IN GANGLION CELL AND INNER PLEXIFORM LAYERS THICKNESS AND RETINAL MICROVASCULATURE IN DIFFERENT STAGES OF GLAUCOMA
}

\author{
By
Mohamed Abd El-Monem Mahdy, Mohamed Abd El-Badiea Rashed, and Mahmoud Ali Metwaly Omran

Department of Ophthalmology, Faculty of Medicine, Al-Azhar University

Corresponding author: Mahmoud Ali Metwaly Omran,

E-mail: drmahmoudali426@ gmail.com; Mobile: 01122384565

\begin{abstract}
Background: Primary open angle glaucoma (POAG) is an optic neuropathy characterized by progressive degeneration of retinal ganglion cells (RGC) and their axons, which results in characteristic excavation of the neuroretinal rim with corresponding visual field (VF) deficits. Optical coherence tomography angiography (OCTA) is a novel imaging modality that can detect vascular flow of the retina and choroid in great detail. The ability to segment OCT angiograms into the different vascular layers may improve understanding of disease pathogenesis.

Objective: To evaluate the correlation between Ganglion Cell and Inner Plexiform Layers thickness using optical coherence tomography (OCT) and the macular microvasculature density in different stages of primary open angle glaucoma using optical coherence tomography angiography (OCTA).

Subjects and Methods: The study was performed on 80 eyes of 48 subjects including 20 eyes of 11 controls, and 60 eyes of 37 POAG cases which were divided into 3 groups according to Hodapp,Parish,Anderson (HP-A) classification; Group1: mild glaucoma (20 eyes), Group 2: moderate glaucoma (20 eyes),Group 3: severe glaucoma (20 eyes).

Results: In our study, we found that there was a significant reduction in Ganglion Cell - Inner Plexiform Layer (GCIPL) thickness and macular VD in patients with POAG which increased with increasing glaucoma severity, also we found that OCT and OCTA parametrs were significantly differentiate between normal and POAG cases and also between different stages of POAG.

Also we found that an OCTA was an important diagnostic tool in diagnosing mild cases of POAG and to differentiate between mild and moderate cases of POAG,in contrast to OCT in which there was no significant differance between mild and moderate cases of POAG. OCTA seems to be a good candidate for diagnosis and follow-up of glaucoma, complementing the results provided by OCT and visual field testing.

Conclusion: Significant differences between eyes with POAG and normal eyes in terms of the macular GCIPL thickness and microvasculature density (VD) suggest that the macular GCIPL thickness and the retinal capillary vessel area density may be reliable indicators of glaucoma severity.
\end{abstract}

Keywords: Primary Open angle glaucoma, Ganglion Cell - Inner Plexiform Layer, optical coherence tomography (OCT), optical coherence tomography angiography (OCTA), vessel density (VD). 


\section{INTRODUCTION}

Glaucoma is a leading cause of irreversible blindness worldwide and is associated with characteristic damage to the optic nerve and patterns of visual field loss due to retinal ganglion cell (RGC) degeneration. Intraocular pressure (IOP) is regarded as the major risk factor.

There are estimated to be over 60 million people worldwide with glaucomatous optic neuropathy of which 8.4 million are blind. The global incidence of glaucoma is anticipated to increase to 76 million by 2020 and 111.8 million by 2040 (Tham et al., 2014).

The macula is among the most metabolically active of all human tissues and derives its oxygen supply from multiple retinal capillary plexuses. Approximately one-half of retinal ganglion cell somas are concentrated in the macula. They depend on regional capillary networks to meet their high metabolic requirements. Deficiencies in these networks can result in various diseases, such as diabetic retinopathy, retinal vein occlusion, and glaucoma (Shoji et al., 2018).

Macular ganglion cell complex (GCC) parameters have a theoretical advantage over per papillary RNFL parameters in diagnosis, because RGC loss occurs early in the pathogenesis of glaucoma and this early loss typically gives rise to isolated damage in the Para central areas $\left(10^{\circ}-20^{\circ}\right)$. The macular GCC scan is centered on the fovea, covers a $7 \times$ 7-mm grid, and readily detects early GCC loss (Kim et al., 2010).

The Hodapp, Parish, Anderson (H-P-A) classification system is a clinically useful method that considers two criteria: the overall extent of damage using both mean deviation(MD) value and the number of defective points in the Humphrey pattern deviation probability map. In addition the method takes into consideration, the proximity of $\operatorname{defect}(\mathrm{s})$ to fixation. Minimum criteria for diagnosing acquired glaucomatous damage: A Glaucomatous Hemifeild Test outside normal limits on at least two fields; OR A Cluster of three or more non-edge points in a location typical for glaucoma, all of which are depressed on the pattern deviation plot at a $p<5 \%$ level and one of which is depressed at a $\mathrm{p}<1 \%$ level on two consecutive fields; OR Corrected pattern standard deviation that occurs in less than $5 \%$ of normal fields on two consecutive fields (Susanna and Vessani, 2009).

A major drawback of current approaches to glaucoma diagnosis includes the inability to positively diagnose glaucoma before considerable damage to the retina has already occurred. Although RGC apoptosis has been identified as the earliest form of cell death in glaucoma, it is estimated that up to $40 \%$ of RGCs are lost before field defects can be detected using the standard clinical tests (Davis et al., 2016).

OCT is not dependent on patient response and therefore provides objective information on retinal layers' thickness, with a high repeatability and reproducibility (Shin et al., 2017). However, there is a floor effect for OCT in advanced glaucoma, when the OCT parameters reach a base level beyond which little change is seen with increasing severity of glaucoma (Rao et al., 2017). 
Optical coherence tomography angiography (OCTA) is non-invasive imaging modality that detects blood flow through the motion contrast generated by red blood cells. It can be used to provide a quantitative assessment of the microcirculation of the retina and choroid in various layers, this technology has the potential to bring forward new information about the pathophysiology of glaucoma, as well as to help clinicians with glaucoma diagnosis and management (Lee et al., 2016).

A new technology for diagnosis and follow-up of glaucoma that can avoid the limitations of OCT and visual field is lacking. OCTA seems to be a good candidate for such a role. So, in this study, we focused on how OCTA can help the clinicians in glaucoma diagnosis and follow-up, complementing the results provided by OCT and visual field testing.

\section{SUBJECTS AND METHODS}

A cross-sectional, observational study was performed on 37 patients (60 eyes) with primary open angle glaucoma (POAG) presenting to the glaucoma sub specialty clinics of Al azhar University Hospitals and 11age matched normal participants (20 eyes) presenting to the ophthalmic outpatient clinics of Al-Azhar University hospitals over the period from january 2019 to august 2019. The research protocol was approved by the institutional review board and carried out in accordance with the Declaration of Helsinki. Written informed consent was obtained from each subject following an explanation of the nature of the study.

Eyes with POAG were divided according to the Hodapp- Parrish-Anderson grading scale of Visual field defect severity into an early-stage (mild) POAG group, moderate stage POAG group and an advanced-stage POAG group.

The eyes of participants were classified into 4 groups: The control group (20 eyes) had: intraocular pressure (IOP) of $21 \mathrm{~mm} \mathrm{Hg}$ or less, a normal Humphrey SITA 24-2 standard visual field; normal $\mathrm{ONH}$, defined as intact neuroretinal rim without peripapillary hemorrhages, notches, localized pallor, or RNFL defects; an open anterior chamber angle; and no history of chronic ocular or systemic disease. Early-stage (mild) POAG group (20 eyes) had Mean Defect (MD) $<-5 \mathrm{~dB}$ and $<18$ points below $5 \%$, or $<10$ points below $1 \%$ on PSD, and No central points $<20 \mathrm{~dB}$ in Humphrey visual field testing. Moderate stage POAG group (20 eyes) had Mean Defect $-5 \mathrm{~dB}$ to $<-10 \mathrm{~dB}$, OR 18-36 points below $5 \%$,OR 10-20 below 1\% on PSD, OR Central points between 10-20 dB in one hemifield in Humphrey visual field testing. Advanced-stage POAG group (20 eyes) had Mean Defect (MD) $>10 \mathrm{~dB}$ OR $>36$ points below $5 \%$ OR $>20$ points below $1 \%$ on PSD OR $<20 \mathrm{~dB}$ in both hemifields centrally or any point in central 5 degrees $<10 \mathrm{~dB}$ in Humphrey visual field testing.

\section{Inclusion criteria:}

Age: 18 years or older. Primary open angle glaucoma. Patients having Best Corrected Visual Acuity 6/60 or more. Spherical Equivelant (SE) within \pm 5 diopters (D), cylinder refraction within $\pm 3 \mathrm{D}$. 


\section{Exclusion criteria:}

Angle closure, congenital, juvenile, traumatic, Neovascular and inflammatory glaucomas. Significant media opacity that may affect OCT signals. Previous intraocular surgery other than uncomplicated cataract or glaucoma surgery. Patients having other intraocular diseases affecting visual field such as pituitary lesions, demyelinating diseases. Patients having any history or evidence of retinal pathology, diabetes mellitus. Patients on any drug that might affect the blood flow of the retina.

\section{Patient evaluation:}

Patients were evaluated and their demographic data were recorded: age, sex, medical history (diabetes mellitus and hypertension) and surgical history. All patients were subjected to ophthalmic examination of both eyes in the form of: Best corrected visual acuity (BCVA) using Snelle's chart expressed in decimel notation. Slit lamp examination. Refraction using TOPCON KR 800 autorefractometer that was verified manually. Intraocular pressure (IOP) measurement using Goldmann's applanation tonometer. Gonioscopy to assess the anterior chamber angle. Dilated Fundus examination using slit lamp biomicroscopy using 90D lens. Visual field testing using SITA standard algorithm with a 24-2 test pattern; Humphrey Visual Field Analyser II. OCT ganglion cell inner plexiform layer using SS-OCT (DRI OCT Tritonplus, Topcon, Japan). OCT angiography was done using SS-OCT (DRI OCT Tritonplus, Topcon, Japan).

Optical coherence tomography procedure: All of the imaging procedures were performed using SS-OCT (DRI OCT Tritonplus, TOPCON, Japan). It measures the RNFL thickness, the RGC with the IPL (GCIPL), and the GCC. It uses raster scanning of a 7 $\mathrm{mm} 2$ area that is centered on the fovea with a scan density of 256 (horizontal) $\times 512$ (vertical) scans (3D-Macula $7 \times 7 \mathrm{~mm}$ protocol). The GCIPL between the outer boundary of the RNFL and the outer boundary of the inner plexiform layer was measured at the macular region on SS-OCT images using a specific automatic segmentation algorithm.

Swept-source OCT-angiography: All OCTA scans were performed by a single experienced examiner using a swept-source OCT device (DRI OCT Triton plus, TOPCON, Japan). The device operates with a central wavelength of $1050 \mathrm{~nm}$, an acquisition speed of 100,000 A-scans per second, and an axial and transverse resolution of 7 and $20 \mu \mathrm{m}$ in tissue. The scans were taken from a $6 \times 6 \mathrm{~mm}$ cube, with each cube consisting of 320 clusters of four repeated B-scans centered on the fovea. A good image quality is more than 40 according to the OCT manufacturer. The automated segmentation defines the en face slab for the SRL to extend from $2.6 \mu \mathrm{m}$ beneath the internal limiting membrane to $15.6 \mu \mathrm{m}$ beneath the interface of the inner plexiform layer and inner nuclear layer (IPL/INL). The DRL slab was generated from $15.6 \mu \mathrm{m}$ beneath the IPL/INL to $70.2 \mu \mathrm{m}$ beneath IPL/INL. The centration of the fovea was checked for all images. 


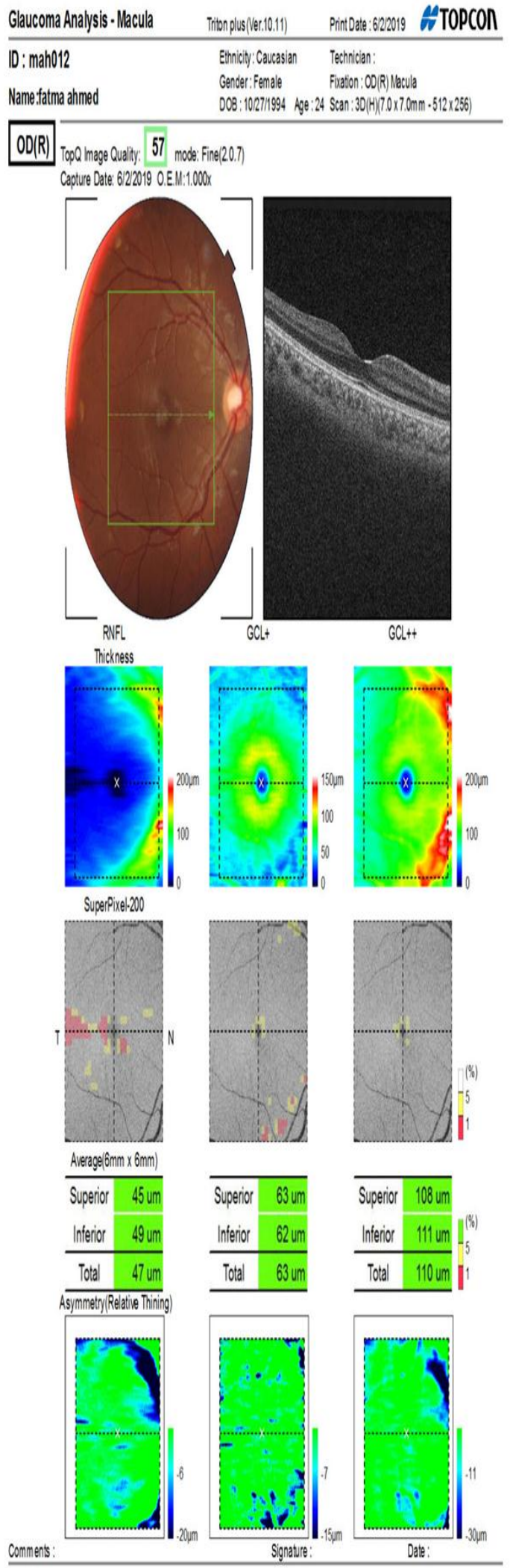


Fig (1): Three dimensions optical coherence tomography. A: Segmentation: $7 \mathrm{~mm} 2$ area centered on the fovea with a scan density of 512 vertical $\times 128$ horizontal scans; B: Thickness map. Average regional thickness is calculated for RNFL, GCL+ (GCL + IPL), GCL++ (RNFL + GCL + IPL). Each cell layer is calculated and compared to the normative database of the device; C: Significance map. From left to right, $10 \times 10$ grid comparison maps covering $6 \mathrm{~mm} \times 6 \mathrm{~mm}$ area of RNFL, GCL+ and GCL++ are shown. The comparison result is displayed with the color in the legend on the right. The background image is red free image; D: Average thickness. From left to right, three average thicknesses of RNFL, GCL+ and GCL++. The top is "Superior" which means average in the upper half area, the middle is "Inferior" which means average in the lower half area, and the bottom is "Total' which means average in the total area. Each average thickness is compared to the normative data and displayed according to color; E: Asymmetry map. From left to right, subtraction thickness maps covering 6 $\mathrm{mm} \times 6 \mathrm{~mm}$ area of RNFL, GCL+ and GCL++ are shown. 


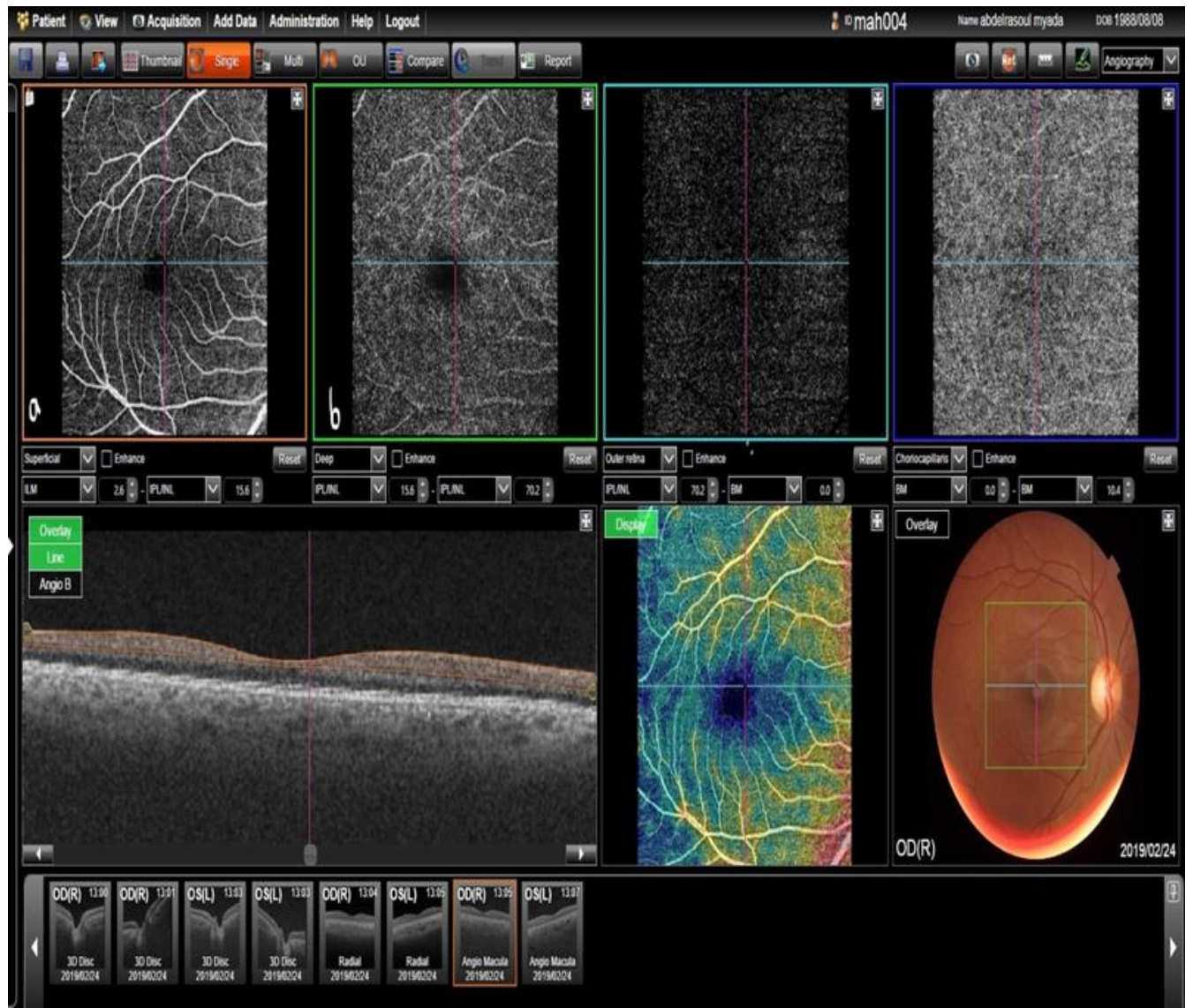

Figure (2): Automated segmentation of the retinal layers. a The superficial retinal layer (SRL) extends from $2.6 \mu \mathrm{m}$ beneath the internal limiting membrane to $15.6 \mu \mathrm{m}$ beneath the interface of the inner plexiform layer and inner nuclear layer (IPL/INL). b The deep retinal layer (DRL) slab was generated from $15.6 \mu \mathrm{m}$ beneath the IPL/INL to $70.2 \mu \mathrm{m}$ beneath IPL/INL.

Quantitative measurements and statistical analysis: For this study, en face slabs of the SRL were used for quantitative analyses. The quantitative analysis was performed using the publically available Image J software (public domain software, National Institutes of Health, Bethesda, Maryland, USA) The SRL en face image was analyzed with and without using OCT device's proprietary artifact removal tool. The Vessel Density
(VD) was expressed as a ratio by taking the total vessel area divided by the total area of the analyzed region in the entire $6 \times 6 \mathrm{~mm}$ scan.

After extracting the original images from the viewing software, the images were then imported into ImageJ. For the VD measurement, we used a binarized image with intensity thresholding with Otsu's thresholding method as implemented in Image J. Otsu's 
method assumes that the image contains two classes of pixels following a bi-modal distribution. It calculates optimum threshold by minimizing intra class variance and maximizing interclass variance. The total number of pixels occupied by vessels was then divided by the total number of pixels from the entire image and the value was expressed as a ratio.

\section{Statistical analysis:}

Data were collected, revised, coded and entered to the Statistical Package for Social Science (SPSS) version 20 and the following were done:

Qualitative data were presented as number and percentages, while quantitative data were presented as mean, standard deviations and ranges. The comparison between two groups with qualitative data were done by using Chi-square test and/or Fisher exact test, Kruskal Wallis test was used instead of Chisquare test when the expected count in any cell was found less than 5 .

The comparison between two independent groups with quantitative data and parametric distribution were done by using Independent t-test.

The comparison between more than two groups with parametric distribution was done by using One Way Analysis of Variance (ANOVA).

\section{RESULTS}

The mean ages of the normal group and POAG group were 44. $36 \pm 11.36$ and $49.11 \pm 12.49$ years respectively. $72.7 \%$ (8 cases) of the normal were females and $27.3 \%$ ( 3 cases) were males, and $78.4 \%$ (29 cases) of POAG group were females and $21.6 \%$ ( 8 cases) were males. There was a highly statistically significant difference between normal group and POAG group as regard BCVA, IOP, VF $(\mathrm{MD} / \mathrm{dB})$ and Vessel density but there is no statistically significant difference between the 2 studied groups as regard Refraction (table 1). 
Table (1): A Comparison between Normal group and POAG group as regard BCVA, Refraction, IOP, VF (MD/dB) and Vessels density (Mean \pm SD\& Range)

\begin{tabular}{|c|c|c|c|}
\hline \multirow{2}{*}{$\begin{array}{l}\text { Groups } \\
\text { Parameters }\end{array}$} & Normal group & Primary open angle glaucoma & \multirow{2}{*}{ P-value } \\
\hline & No. $=20$ & No. $=60$ & \\
\hline \multirow{2}{*}{ BCVA in Decimel } & $0.54 \pm 0.29$ & $0.26 \pm 0.16$ & \multirow{2}{*}{0.00} \\
\hline & $0.17-1$ & $0.01-0.67$ & \\
\hline \multirow{2}{*}{ Refraction } & $-2.39 \pm 1.48$ & $-1.27 \pm 2.60$ & \multirow{2}{*}{0.207} \\
\hline & $-4.5-1$ & $-4.75-4$ & \\
\hline \multirow{2}{*}{ IOP/mmhg } & $16.42 \pm 1.63$ & $-20.53 \pm 2.88$ & \multirow{2}{*}{0.00} \\
\hline & $13-20$ & $15-30$ & \\
\hline \multirow{2}{*}{$\mathrm{VF}(\mathrm{MD} / \mathrm{dB})$} & $0.09 \pm 0.69$ & $-10.22 \pm 3.03$ & \multirow{2}{*}{0.00} \\
\hline & $-1.23-1.02$ & $-29.45-14.84$ & \\
\hline \multirow{2}{*}{ Vessels density } & $57.58 \pm 0.91$ & $49.89 \pm 5.07$ & \multirow{2}{*}{0.00} \\
\hline & $55.88-59.34$ & $37.85-58$ & \\
\hline
\end{tabular}

$\bullet$ Independent t-test; + : Mann Whitney test

There was a highly statistically significant difference between normal group and POAG group as regard Superior and inferior GCIPL thickness (Table2).

The mean superior GCIPL of the normal group and POAG group were
$68.42 \pm 2.60$ and $60.47 \pm 5.35$ micron respectively, while The mean inferior GCIPL of the normal group and POAG group were67.32 \pm 2.81 and $59.77 \pm 4.85$ micron respectively.

Table (2): A Comparison between Normal group and POAG group as regard Superior and inferior GCIPL thickness (Mean \pm SD\& Range)

\begin{tabular}{|l|c|c|c|}
\hline \multirow{2}{*}{ Parameters Groups } & Normal group & Primary open angle glaucoma & \multirow{2}{*}{ P-value } \\
\cline { 2 - 3 } & No. $=\mathbf{2 0}$ & No. $=\mathbf{6 0}$ & \multirow{2}{*}{0.00} \\
\hline \multirow{2}{*}{ Superior GCIPL/ micron } & $68.42 \pm 2.60$ & $60.47 \pm 5.35$ & \multirow{2}{*}{0.00} \\
\cline { 2 - 3 } Inferior GCIPL micron & $65-74$ & $47-70$ & $59.77 \pm 4.85$ \\
\cline { 2 - 3 } & $67.32 \pm 2.81$ & $50-69$ & \\
\hline
\end{tabular}

$\bullet:$ Independent t-test

There were highly statistically significant differences between studied groups as regard all parameters except
BCVA in which there were no statistically significant difference between normal and mild POAG group (table 3 ). 
Table (3): A Comparison between Normal group and POAG groups (mild,moderate and severe) as regard BCVA, Refraction, IOP,VF (MD/dB) and Vessels density(Median(IQR)\&Range)

\begin{tabular}{|c|c|c|c|c|c|}
\hline \multirow{2}{*}{ Parameters } & $\begin{array}{l}\text { Normal } \\
\text { group }\end{array}$ & $\begin{array}{c}\text { Mild } \\
\text { glaucoma }\end{array}$ & $\begin{array}{l}\text { Moderate } \\
\text { glaucoma }\end{array}$ & $\begin{array}{c}\text { Severe } \\
\text { glaucoma }\end{array}$ & \multirow{2}{*}{ P-value } \\
\hline & No. $=20$ & No. $=20$ & No. $=20$ & No. $=20$ & \\
\hline \multirow{2}{*}{ BCVA in Decimel } & $0.54 \pm 0.29$ & $0.41 \pm 0.19$ & $0.21 \pm 0.07$ & $0.18 \pm 0.09$ & \multirow{2}{*}{0.00} \\
\hline & $0.17-1$ & $0.1-0.67$ & $0.1-0.33$ & $0.01-0.33$ & \\
\hline \multirow{2}{*}{ Refraction } & $-2.39 \pm 1.48$ & $-1.26 \pm 2.56$ & $-1.96 \pm 2.66$ & $-0.59 \pm 2.54$ & \multirow{2}{*}{0.131} \\
\hline & $-4.5-1$ & $-4.5-2.75$ & $-4.75-4$ & $-4-3.26$ & \\
\hline \multirow{2}{*}{$\mathrm{IOP} / \mathrm{mmhg}$} & $16.42 \pm 1.63$ & $19.90 \pm 2.27$ & $20.30 \pm 2.30$ & $21.40 \pm 3.75$ & \multirow{2}{*}{0.00} \\
\hline & $13-20$ & $16-24$ & $15-24$ & $15-30$ & \\
\hline \multirow{2}{*}{$\mathrm{VF}(\mathrm{MD} / \mathrm{dB})$} & $0.09 \pm 0.69$ & $-3.23 \pm 0.91$ & $-7.74 \pm 1.25$ & $-19.69 \pm 9.93$ & \multirow{2}{*}{0.00} \\
\hline & $-1.23-1.02$ & $-4.65--2$ & $-10--6.15$ & $-29.45-14.84$ & \\
\hline \multirow[b]{2}{*}{ Vessels density } & $57.58 \pm 0.91$ & $55.56 \pm 1.28$ & $49.45 \pm 2.35$ & $44.66 \pm 3.12$ & \multirow[b]{2}{*}{0.00} \\
\hline & $\begin{array}{c}55.88- \\
59.34\end{array}$ & $53.15-58$ & $45.92-55.43$ & $37.85-49.47$ & \\
\hline
\end{tabular}

$\bullet:$ One Way ANOVA test; + : Kruskal Wallis test

\begin{tabular}{|l|c|c|c|}
\hline \multirow{2}{*}{} & \multicolumn{3}{|c|}{ Post Hoc analysis } \\
\cline { 2 - 4 } & P1 & P2 & P3 \\
\hline IOP/mmhg & $\mathbf{0 . 0 0 0}$ & $\mathbf{0 . 0 0 0}$ & $\mathbf{0 . 0 0 0}$ \\
\hline VF $(\mathrm{MD} / \mathrm{dB})$ & $\mathbf{0 . 0 0 0}$ & $\mathbf{0 . 0 0 0}$ & $\mathbf{0 . 0 0 0}$ \\
\hline Vessels density & $\mathbf{0 . 0 0 3}$ & $\mathbf{0 . 0 0 0}$ & $\mathbf{0 . 0 0 0}$ \\
\hline
\end{tabular}

P1: Normal Vs Mild

P2: Normal Vs Moderate

P3: Normal Vs Severe

There was a highly statistically significant difference between normal VS mild group, normal VS moderate group, and normal VS severe group as regard Superior and inferior GCIPL thickness. Also there was a highly statistically significant difference between Mild Vs
Severe and Moderate Vs Severe G groups as regard Superior and inferior GCIPLthickness but there was no statistically significant difference between Mild Vs Moderate groups as regard Superior and inferior GCIPL thickness (Table 4).

Table (4): A Comparison between Normal group and POAG groups (mild,moderate and severe) as regard Superior and inferior GCIPL thikness (Mean \pm SD\& Range)

\begin{tabular}{|l|c|c|c|c|c|}
\hline \multirow{2}{*}{ Parameters Groups } & $\begin{array}{c}\text { Normal } \\
\text { group }\end{array}$ & $\begin{array}{c}\text { Mild } \\
\text { glaucoma }\end{array}$ & $\begin{array}{c}\text { Moderate } \\
\text { glaucoma }\end{array}$ & $\begin{array}{c}\text { Severe } \\
\text { glaucoma }\end{array}$ & \multirow{2}{*}{ P-value } \\
\cline { 2 - 6 } & No. = 20 & No. = 20 & No. = 20 & No. = 20 & \\
\hline \multirow{2}{*}{ Superior GCIPL/ micron } & $68.42 \pm 2.60$ & $63.05 \pm 4.05$ & $63.15 \pm 2.50$ & $55.20 \pm 4.75$ & \multirow{2}{*}{0.000} \\
\cline { 2 - 6 } & $65-74$ & $55-70$ & $59-68$ & $47-63$ & \\
\hline \multirow{2}{*}{ Inferior GCIPL /micron } & $67.32 \pm 2.81$ & $62.75 \pm 2.77$ & $61.65 \pm 3.70$ & $54.90 \pm 3.70$ & \multirow{2}{*}{0.000} \\
\cline { 2 - 5 } & $62-72$ & $56-67$ & $51-69$ & $50-62$ & \\
\hline
\end{tabular}

: One Way ANOVA test 


\begin{tabular}{|c|c|c|c|c|c|c|}
\hline & \multicolumn{3}{|c|}{ Post Hoc analysis by LSD } & \multirow[b]{2}{*}{$\mathbf{P 4}$} & \multirow[b]{2}{*}{ P5 } & \multirow[b]{2}{*}{ P6 } \\
\hline & P1 & $\mathbf{P 2}$ & $\mathbf{P 3}$ & & & \\
\hline Superior GCIPL/ micron & 0.000 & 0.000 & 0.000 & 0.935 & 0.000 & 0.000 \\
\hline Inferior GCIPL/ micron & 0.000 & 0.000 & 0.000 & 0.313 & 0.000 & 0.000 \\
\hline $\begin{array}{l}\text { Normal Vs Mild } \\
\text { Normal Vs Moderate } \\
\text { Normal Vs Severe }\end{array}$ & $\begin{array}{l}\text { P5: } \\
\text { P6 }\end{array}$ & $\begin{array}{l}\text { d Vs M } \\
\text { d Vs Se } \\
\text { derate }\end{array}$ & & & & \\
\hline
\end{tabular}

There was a highly statistically significant difference between mild, moderate and severe POAG groups as regard $\mathrm{VF}(\mathrm{MD} / \mathrm{dB})$ and Vessels density parameters. Also there was a highly statistically significant difference between
Mild Vs Moderate groups and Mild Vs Severe groups as regard BCVA but there was no statistically significant difference between Moderate Vs Severe groups (Table 5).

Table (5): A Comparison between POAG groups (mild,moderate, severe glaucomas) as regard $\mathrm{BCVA}, \mathrm{VF}(\mathrm{Md} / \mathrm{dB})$ and Vessels density. (Mean $\pm \mathrm{SD} \&$ Range)

\begin{tabular}{|c|c|c|c|c|}
\hline \multirow{2}{*}{ Parameters } & $\begin{array}{c}\text { Mild } \\
\text { glaucoma }\end{array}$ & $\begin{array}{l}\text { Moderate } \\
\text { glaucoma }\end{array}$ & Severe glaucoma & \multirow[t]{2}{*}{ P-value } \\
\hline & No.\% & No.\% & No.\% & \\
\hline \multirow{2}{*}{ BCVA in Decimel } & $0.41 \pm 0.19$ & $0.21 \pm 0.07$ & $0.18 \pm 0.09$ & \multirow{2}{*}{0.000} \\
\hline & $0.1-0.67$ & $0.1-0.33$ & $0.01-0.33$ & \\
\hline \multirow{2}{*}{$\mathrm{VF}(\mathrm{MD} / \mathrm{dB})$} & $-3.23 \pm 0.91$ & $-7.74 \pm 1.25$ & $-19.69 \pm 9.93$ & \multirow{2}{*}{0.000} \\
\hline & $-4.65--2$ & $-10--6.15$ & $-29.45-14.84$ & \\
\hline \multirow{2}{*}{ Vessels density } & $55.56 \pm 1.28$ & $49.45 \pm 2.35$ & $44.66 \pm 3.12$ & \multirow{2}{*}{0.000} \\
\hline & $53.15-58$ & $45.92-55.43$ & $37.85-49.47$ & \\
\hline
\end{tabular}

•: One Way ANOVA test; + : Kruskal Wallis test

\begin{tabular}{|l|c|c|c|}
\hline \multirow{2}{*}{} & \multicolumn{3}{|c|}{ Post Hoc analysis } \\
\cline { 2 - 4 } & P1 & P2 & P3 \\
\hline BCVA in Decimel & $\mathbf{0 . 0 0 0}$ & $\mathbf{0 . 0 0 0}$ & $\mathbf{0 . 1 9 1}$ \\
\hline VF (MD/dB) & $\mathbf{0 . 0 0 0}$ & $\mathbf{0 . 0 0 0}$ & $\mathbf{0 . 0 0 0}$ \\
\hline Vessels density & $\mathbf{0 . 0 0 0}$ & $\mathbf{0 . 0 0 0}$ & $\mathbf{0 . 0 0 0}$ \\
\hline
\end{tabular}

P1: Mild Vs Moderate

P2: Mild Vs Severe

P3: Moderate Vs Severe

\section{DISCUSSION}

Primary open angle glaucoma (POAG) is an optic neuropathy characterized by progressive degeneration of retinal ganglion cells (RGC) and its axons, which results in characteristic excavation of the neuroretinal rim with corresponding visual field (VF) deficits (Weinreb et al., 2014).

Several studies have suggested that vascular factors contribute to the development and progression of glaucomatous optic neuropathy and that vascular dysfunction is an important cause of POAG (Hwang et al., 2012).

Studies using optical coherence tomography angiography (OCTA) have mainly focused on the microcirculation of the optic disc and peripapillary region, and have demonstrated reduced microcirculation in glaucoma (Chen et al., 2016), but less attention has been paid to 
the microcirculation of the macula in OCTA glaucoma studies thus far (Rao et al., 2016).

For this reason, in our study, vessel density measurements of the superficial capillary plexus (SCP) using OCTA were compared with structural measurements of ganglion cell -inner plexiform layer thickness using OCT in normal subjects and POAG patients of different severity.

In our study, we found that structural parameters including superior and inferior GCIPL thickness was significantly reduced in POAG groups compared to normal control, Also there was a highly significant difference between Mild Vs Severe and Moderate Vs Severe Glaucoma groups as regard Superior and inferior GCIPL thickness, but there is no statistically significant difference between Mild Vs Moderate glaucoma groups as regard Superior and inferior GCIPL thickness.

As regard OCTA parameters, we found that the macular capillary vessel area density of SCP was lower in eyes with POAG than in normal eyes. Also, there was a significant difference between Mild Vs moderate, Mild Vs Severe and Moderate Vs Severe Glaucoma groups.

The macular vessel area density was more strongly correlated with the inner retinal layer thickness than with the full retinal layer thickness. In our study, the inner retinal layer was defined as RGC, and IPL. One possible explanation for these results was that most RGCs resided in the inner retinal layers, which completely obtain their oxygen supply from the superficial retinal capillary plexus.
Also we found that an OCTA was an important diagnostic tool in diagnosing mild cases of POAG and to differentiate between mild and moderate cases of POAG, in contrast to OCT in which there was no significant difference between mild and moderate cases of POAG. But unlike retinal thickness map data, the macular capillary vessel area density cannot be divided into hemispherical or regional measurements. Therefore, we could not assess a focal correspondence among capillary network defects and structural damage.

Previous investigations have indicated a possible relationship between vascular impairment and glaucoma (Caprioli and Coleman, 2010). However, the association of macular vascular structure with glaucoma has rarely been studied.

Takusagawa et al. (2017) reported that decreased superficial VD was observed in patients of POAG, in addition there was a higher correlation between GCC thickness and SVC vessel density. But this study differed from our study in which Takusagawa et al. included the RNFL in both the structural and perfusion measures, increasing the total anatomic structures and corresponding microvasculature being assessed that are affected by glaucoma, while $X u$ et al. (2018) found whole vessel-layer defects in POAG and Normal Tension Glaucoma patients.

$X u$ et al., (2016) study in which the macular VD and retinal thickness were measured, those eyes with POAG had a lower macular VD, which was strongly associated with more severe hemimacular VF defect and thinner corresponding retinal thickness; these findings imply that 
a diminished macular microvasculature network is closely associated with structural and functional glaucomatous damage.

These results are in agreement with findings of Liu et al. (2015) which showed that glaucomatous eyes had decreased peripapillary retinal perfusion on OCT angiograms. Our findings are also supported by the results of Wang et al. (2009), which showed decreased retinal perfusion in glaucomatous eyes, as measured with Doppler FD-OCT. However, these two studies mainly concentrated on hemodynamic parameters of the vessels that supply the ONH.

In contrast, Burgansky-Eliash et al. (2016) found no significant difference in the macular hemodynamic parameters, including the arterial and venous velocities, between eyes with Early Glaucoma and Advanced Glaucoma. Their measurements were made using a retinal function imager, which is limited to measuring blood velocity in mediumsized vessels. This may explain why their results differed from ours, because glaucomatous vascular impairment may begin in the capillary network.

In contrast, the outer one-third of the retina has oxygen and nutrients supplied by choroidal circulation. Therefore, the inner retinal layer, especially the RGC is more susceptible to damage from decreased retinal perfusion than the retina as a whole. In the present study, our data suggest that ganglion cell loss may partly result from an attenuated retinal microcirculation network in eyes with POAG.

\section{CONCLUSION}

In conclusion, significant difference between eyes with POAG and normal eyes in terms of the GCIPL thickness and macular VD suggest that both are involved in the etiology and progression of glaucoma. Therefore, the GCIPL thickness and the retinal capillary vessel area density may be reliable indicators of glaucoma severity.

\section{REFERENCES}

1. Burgansky-Eliash Z, Bartov E, Barak A, Grinvald A and Gaton D. (2016): Bloodflow velocity in glaucoma patients measured with the retinal function imager. Current Eye Research, 41(7):965-970.

2. Caprioli J and Coleman AL. (2010): "Blood pressure, perfusion pressure, and glaucoma," American Journal of Ophthalmology, 149: 704-712.

3. Chen CL, Zhang A, Bojikian KD, Joanne C, Johnstone MA and Bojikian KD. (2016): Peripapillary Retinal Nerve Fiber Layer Vascular Microcirculation in Glaucoma Using Optical Coherence Tomography Based Microangiography. Investigative Opthalmology and Visual Science, 57(4): 475-485.

4. Davis BM, Crawley L, Pahlitzsch M, Javaid F and Cordeiro MF. (2016): Glaucoma: the retina and beyond. Acta Neuropathology, 132(6):807-826.

5. Hwang JC, Konduru R, Zhang X, Tan OU, Sadda SR, Greenfeild DS and Varma R. (2012): Relationship among visual field, blood flow, and neural structure measurements in glaucoma. Investigative Opthalmology and Visual Science, 53(6):3020-3026.

6. Kim NR, Lee ES, Seong GJ, Kim JH, An HG and Kim CY. (2010): StructureFunction Relationship and Diagnostic Value of Macular Ganglion Cell Complex Measurement Using Fourier-Domain OCT in Glaucoma. Investigative Opthalmology and Visual Science, 51(9):4646-4651. 
7. Lee EJ, Lee KM, Lee SH and Kim TW. (2016): OCT angiography of the peripapillary retina in primary open-angle glaucoma. Investigative Opthalmology and Visual Science , 57(14): 6265-6270.

8. Liu L, Jia Y, Takusagawa HL, Pechauer AD, Edmunds B , Morrison JC ,Huang D and Lombardi L. (2015): Optical coherence tomography angiography of the peripapillary retina in glaucoma. JAMA Ophthalmology, 133(9):1045-1052.

9. Rao HL, Pradhan ZS, Weinreb RN, Reddy HB, Riyazuddin M, Dasari S and Webers CA. (2016): Regional Comparisons of Optical Coherence Tomography Angiography Vessel Density in Primary Open-Angle Glaucoma. American Journal of Ophthalmology, 171(6):75-83.

10. Rao HL, Pradhan ZS, Weinreb RN, Riyazuddin M, Dasari S, Mansouri K, Puttaiah NK and Webers CA. (2017): Vessel density and structural measurements of optical coherence tomography in primary angle closure and primary angle closure glaucoma. American Journal of Ophthalmology, 177(3): 106-115.

11. Shin JW, Lee J, Kwon J, Choi J and Kook MS. (2017): Regional vascular density-visual field sensitivity relationship in glaucoma according to disease severity. British Journal of Ophthalmology, 101(12): 1666-1672.

12. Shoji T, Yoshikawa Y, Kanno J, Ishii H, Ibuki H, Ozki K and Kimura I. (2018): Reproducibility of Macular Vessel Density Calculations Via Imaging With Two Different Swept-Source Optical Coherence Tomography Angiography Systems. Translational Vision Science \& Technology, 7(6):31 -38.
13. Susanna $R$ and Vessani RM. (2009): Staging glaucoma patient: why and how? Open Ophthalmol J, 3:59-64.

14. Takusagawa HL, Liu L, Ma KN, Jai Y, Gao SS, Zhang $M$, Parikh $M$ and Huang D. (2017): Projection-Resolved Optical Coherence Tomography Angiography of Macular Retinal Circulation in Glaucoma. Ophthalmology, 124(11):1589-1599.

15. Tham YC, Li X, Wong TY, Quagly HA, Aung $T$ and Cheng CY. (2014): Global Prevalence of Glaucoma and Projections of Glaucoma Burden through 2040. A Systematic Review and Meta-Analysis. Ophthalmology, 121(11):2081-2090.

16. Wang Y, Lu A, Gil-Flamer J, Tan O, Izatt JA and Huang D. (2009): Measurement of total blood flow in the normal human retina using Doppler Fourier-domain optical coherence tomography. British Journal of Ophthalmology, 93(5):634-637.

17. Weinreb RN, Aung $T$ and Medeiros FA. (2014): The pathophysiology and treatment of glaucoma: a review. JAMA ophthalmology, 311(18):1901-1911.

18. Kong $X$, Sun $X$ and Jiang C. (2016): Macular microvasculature alterations in patients with primary open-angle glaucoma: A cross-sectional study. Medicine (Baltimore), 95(33): e4341.

19. Xu H, Zhai R, Zong $Y$, Kong $X$, Jiang $C$ and Sun X. (2018): "Comparison of retinal microvascular changes in eyes with hightension glaucoma or normal-tension glaucoma: a quantitative optic coherence tomography angiographic study," Graefe's Archive for Clinical and Experimental Ophthalmology, 256(6): 1179-1186. 


\section{التغير ات في طبقتى الخلايا العقدية و الضفيرة الداخلية والأوعية الدموية الدقيقة بالثبكية في المر احل المختلفة لمرض المياه الزرقاء}

محمد عبدالمنعم مهدي، محمد عبدالبديع راشد، محمود علي متولي عمران قسم طب وجراحة العيون، كلية الطب، جامعة الأزهر

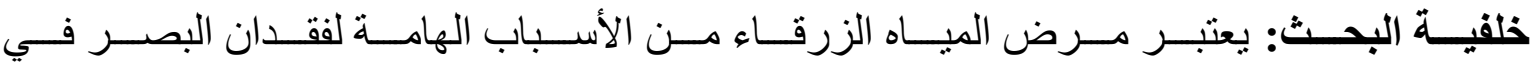

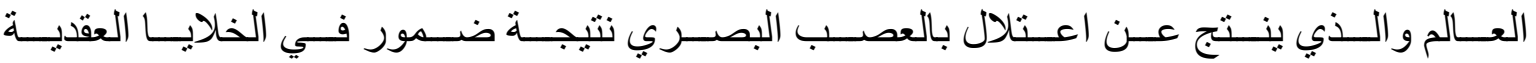

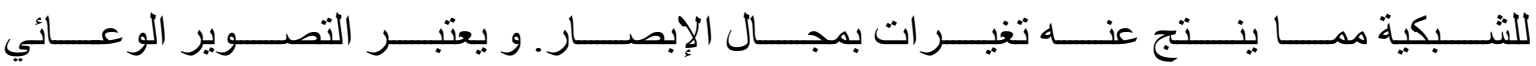

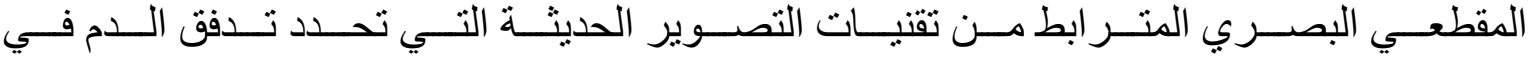

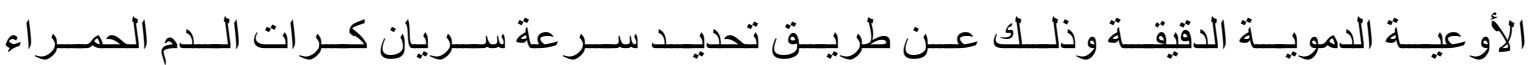
مما قد يساعد في فهم الاسباب التي تؤدي الي مرض المياه الزرقاء.

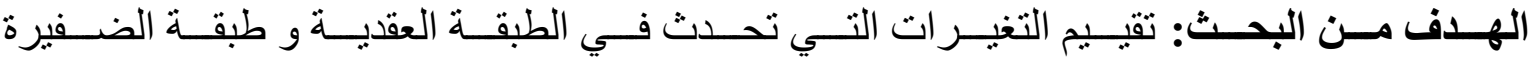

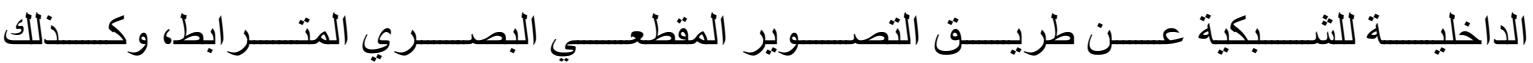

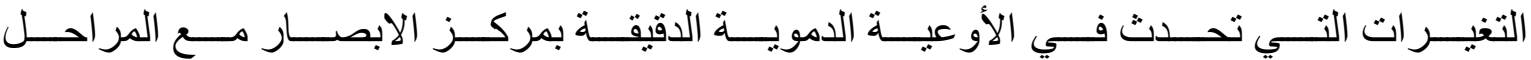

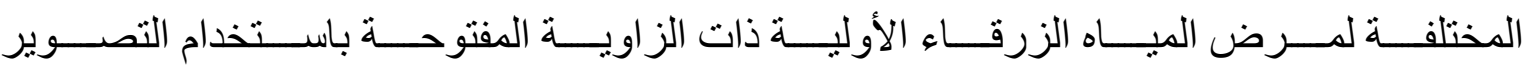
الو عائي المقطعي البصري المتر ابط.

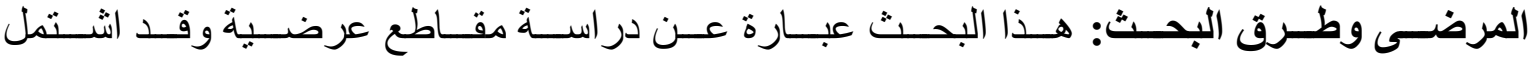

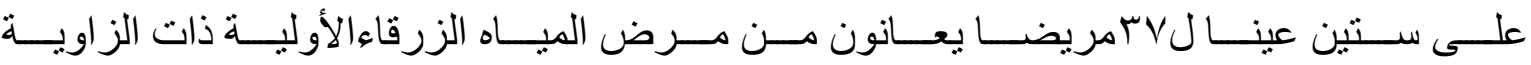

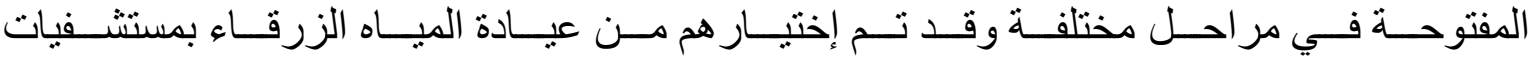

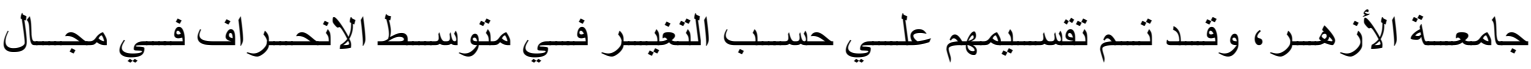

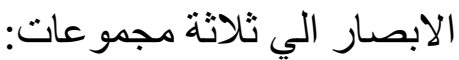

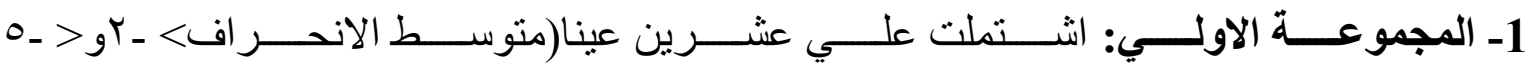
ديسيل).

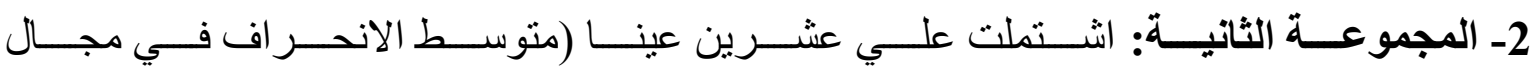
الابصار من > ـ مديسيل و > ـ • ( ديسيل). 


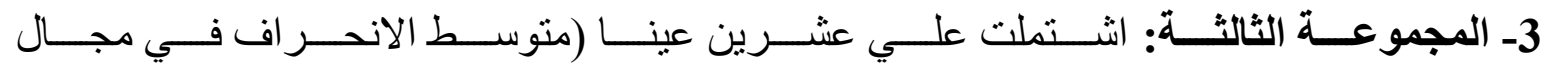
الابصار من > ـ • ( ديسييل).

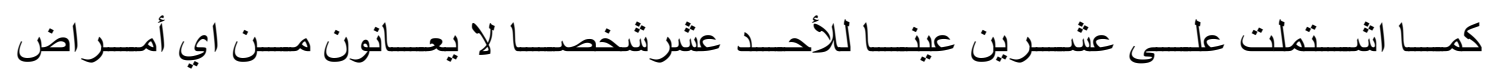

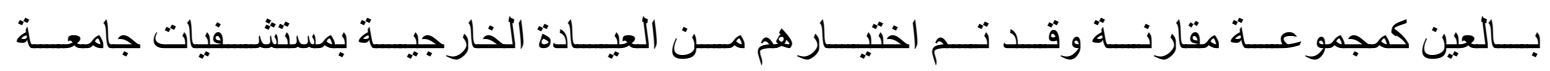
الأزهر.

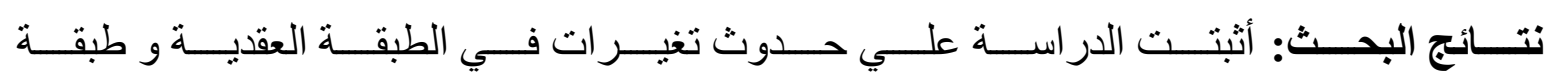

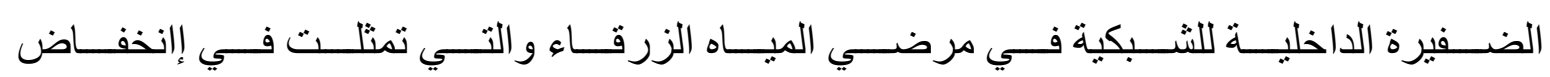

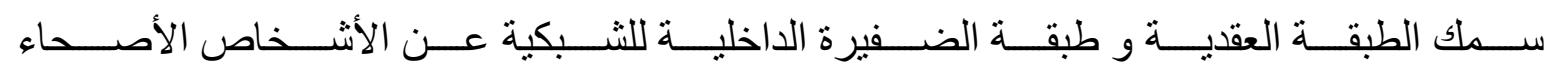

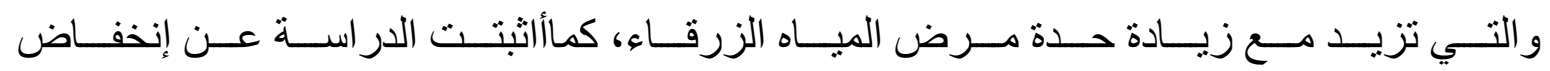
كثافة الأو عية الدموية بماقولة العين نتيجة لهذا المرض.

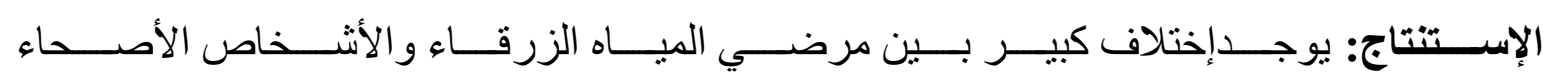

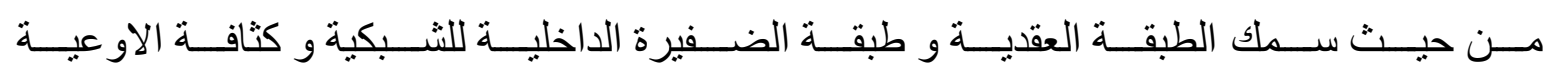
الدموية بماقولة العين مما يدل علي تأثر هم بمرض والم المياه الزرقاء. 